\title{
SEISMIC RESPONSE OF STRAIGHT LINE TYPE AND BROKEN LINE TYPE TRANSMISSION LINES SUBJECTED TO NON-UNIFORM SEISMIC EXCITATIONS
}

\author{
L. Tian ${ }^{1, *}$, R.S. Ma ${ }^{1}$, H.N. $\mathrm{Li}^{2}$ and P. Zhang ${ }^{3}$ \\ ${ }^{1}$ School of Civil and Hydraulic Engineering, Shandong University, Jinan, PR China \\ ${ }^{2}$ Professor, Faculty of Infrastructure Engineering, Dalian University of Technology, Dalian, PR China \\ ${ }^{3}$ Faculty of Infrastructure Engineering, Dalian University of Technology, Dalian, PR China \\ *(Corresponding author: E-mail: tianli@sdu.edu.cn)
}

Received: 15 November 2012; Revised: 12 October 2012; Accepted: 18 October 2012

\begin{abstract}
Seismic responses of straight line type and broken line type transmission tower-line systems subjected to non-uniform seismic excitations are studied in this paper. Three-dimensional finite element models of the straight line type and broken line type transmission tower-line coupled systems are established, respectively. Based on power spectral density function, coherency loss function and code for design of seismic of electrical installations, spatial variation of seismic ground motions are synthesized. Using nonlinear time history analysis method, the influence of wave passage effect, coherency loss effect and different local site effect on the seismic response of two type transmission tower-line systems are investigated, respectively. The results show that the assumption of uniform ground motion could not provide accurate responses of the two type transmission tower-line systems. Non-uniform seismic excitations increase the axial force of transmission tower, and the vertical displacement and tension force of transmission lines. Neglecting these effects will underestimate the response of the two type transmission tower-line systems. The effect of non-uniform ground motions should be considered in seismic design for the straight line type and broken line type transmission lines practical engineering.
\end{abstract}

Keywords: non-uniform seismic excitations, transmission tower-line system, nonlinear time history, wave passage effect, coherency loss effect, local site effect

\section{INTRODUCTION}

Due to the influence of buildings and other important regions, or to prevent the collapse of straight line type, transmission lines are often arranged as a broken line type in practical engineering. Because of the importance of an angle tower, it is necessary to study the seismic response of the broken line type transmission line (Yin et al. [1]). With the voltage and capacity of transmission line improving, the height of transmission tower and the span of transmission line increase, and the spans of most transmission lines are larger than $100 \mathrm{~m}$. The ground motions at the bottom of all towers are different because of the difference in arrival times of seismic waves at different supports, the coherency loss effect owing to reflections and refractions of the waves in the heterogeneous media of the ground, and the local site effect due to different local soil properties (Zerva and Harada [2]).

In recent decades, the transmission tower-line systems were often destroyed during earthquake, and many studies about the seismic responses of transmission lines have been conducted. Ghobarah et al. (Ghobarah et al. [3]) investigated the effect of multi-support excitations on the lateral responses of overhead power transmission lines, and transmission towers were modeled by space truss elements and the cables were modeled by straight two node elements. Li et al. [4, 5, 6] have completed a number of investigations on seismic problems of coupled system of long-span transmission towers. Tian et al. [7] synthesized multi-support time histories of earthquake ground motion and analyzed the power transmission tower-line system under multi-support excitations considering traveling-wave and coherency loss effect, and the results showed that it was necessary to consider multiple support excitations in transmission tower-line system analysis. In all these studies, the transmission tower-line systems were assumed to the straight line type structure. There 
is no study about the seismic response of the broken line type structure, not to mention the seismic analysis of this type structure under non-uniform seismic excitations.

Based on the above research, seismic response of the broken line type transmission tower-line system subjected to non-uniform seismic excitations is performed using nonlinear time history analytical method. In order to compare with the seismic response of the broken line type structure, the response of the straight line type system is also analyzed. According to a practical engineering, the finite element models of two types are established, respectively. The transmission towers are modeled by beam elements, while the transmission lines are modeled by cable elements that account for the geometric nonlinear of cable structures. Non-uniform seismic ground motions are simulated considering power spectral density function, coherency loss function and code for design of seismic of electrical installations. The influence of wave passage effect, coherency loss effect and different local site effect on seismic response of the straight line type and broken line type transmission tower-line systems are investigated, respectively.

\section{STRUCTURAL MODEL}

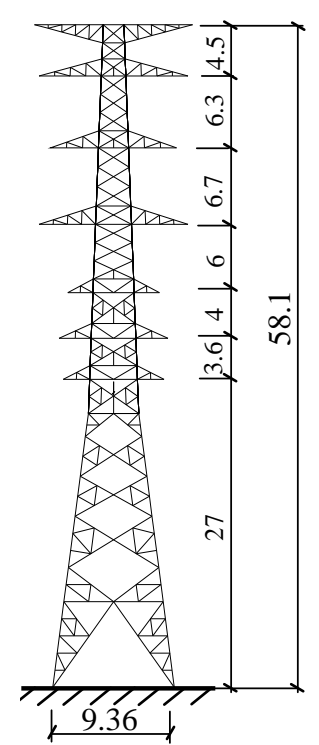

Figure 1. Tower Size (m)

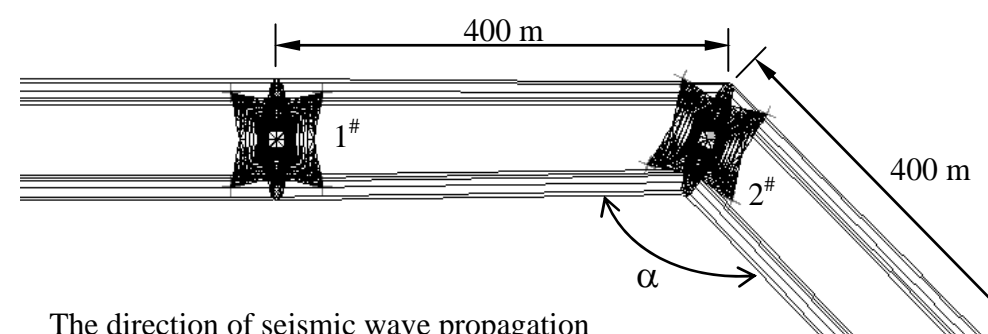

The direction of seismic wave propagation

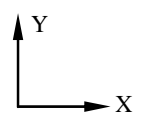

Figure 2. Schematic Diagram of Transmission Line

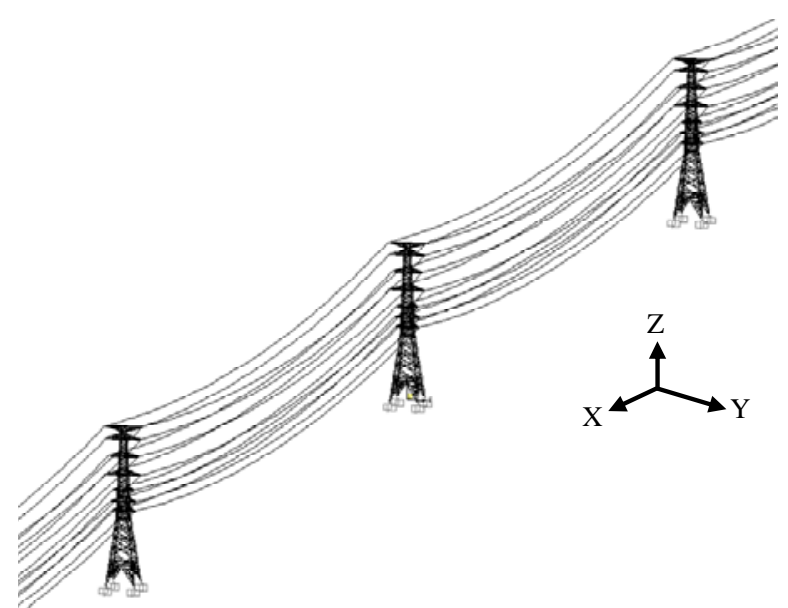

(a) Straight Line Type

(b) Broken Line Type

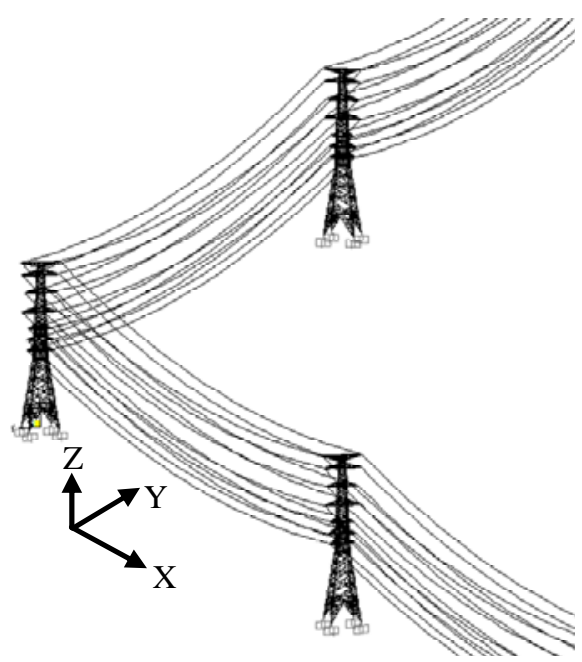

Figure 3. Three-dimensional Finite Element Model of Three Towers and Four-span Lines Coupled System

Figure 1 shows the tower size. The tower is $58.1 \mathrm{~m}$ high, and its weight is approximately $30 \mathrm{t}$. The 
structural members of the tower are made of angle steel with the elastic modulus of $206 \mathrm{GPa}$. The schematic diagram of transmission line is shown in Figure 2. It can be seen from the Figure 2 that the angle $\alpha$ of the broken line type and straight line type transmission tower line systems are $150^{\circ}$ and $180^{\circ}$, respectively. The direction of seismic wave propagation can be seen in Figure 2. Using SAP2000 software, three-dimensional finite element tower-line system is established according to a practical project. Figure 3 shows the three-dimensional finite element model of three towers and four-span lines coupled system, and the straight line type and broken line type of transmission tower line system are established, respectively. The tower is modeled by 1883 space beam members and 727 nodes, and the connections of members are rigid. It has been approved that the numerical results of transmission tower according to beam element are close to the test results (Deng et al. [8]), so the beam element are selected for the simulation of transmission tower. The types of transmission ground line and conductor are JLB40-150, LGJ-400/35 and LGJ-240/30, respectively. The upper 8 cables are ground lines and lower 48 cables are two bundled conductor. The spans to adjacent towers are all $400 \mathrm{~m}$. The base points of the transmission tower are fixed to the ground and the connections between transmission towers and lines are hinged by insulators. The transmission lines from upper to down are numbered (1), (2), (3), (4), (5), (6) and (7), respectively.

The initial axial force and large deformation effect of cable are taken into consideration. Under self weight, the cable spatial configuration is a catenary. Based on the coordinate system illustrated in Figure 4, the mathematical expression used to define the initial geometry of the cable profile is given in the following form (Shen et al. [9])

$$
z=\frac{H}{q}|\cosh (\alpha)-\cosh | \frac{2 \beta x}{l}-\alpha||
$$

where, $\alpha=\sinh ^{-1}\left|\frac{\beta(c / l)}{\sin (\beta)}\right|+\beta, \quad \beta=\frac{q l}{2 H}$, in which $H$ represents initial horizontal tension which can be obtained from a preliminary static analysis, and $q$ denotes uniformly distributed gravity loads along the transmission line.

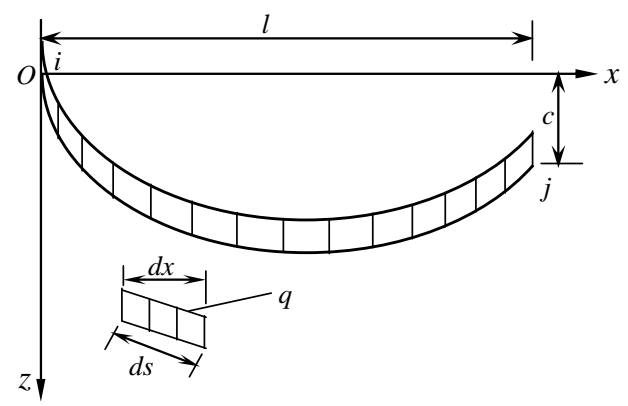

Figure 4. Coordinates of a Single Cable under Self-weight

\section{SIMULATION OF SPATIALLY VARYING GROUND MOTIONS}

The ground motion cross power spectral density function of spatial ground motions at point $i$ and $j$ on the ground surface can be written as

$S_{i j}(\omega)=S_{g}(\omega) \gamma_{i j}\left(\omega, d_{i j}\right)$

where, $S_{g}(\omega)$ is a power spectral density function. $\gamma_{i j}\left(\omega, d_{i j}\right)$ is an empirical coherency 
function.

\subsection{Power Spectrum Density Function}

Clough-Penzien model is selected (Clough and Penzien [10]), and its power spectral density function can be expressed as

$$
S_{g}(\omega)=\frac{\omega_{g}{ }^{4}+4 \xi_{g}{ }^{2} \omega_{g}{ }^{2} \omega^{2}}{\left(\omega_{g}{ }^{2}-\omega^{2}\right)^{2}+4 \xi_{g}{ }^{2} \omega_{g}{ }^{2} \omega^{2}} \cdot \frac{\omega^{4}}{\left(\omega_{f}{ }^{2}-\omega^{2}\right)^{2}+4 \xi_{f}{ }^{2} \omega_{f}{ }^{2} \omega^{2}} S_{0}
$$

in which $S_{0}$ is a scale factor depending on the ground motion intensity, $\omega_{g}$ and $\xi_{g}$ are the predominant frequency and damping ratio of the first filter, $\omega_{f}$ and $\xi_{f}$ are those of the second filter. Reference (Tian and $\mathrm{Li}$ [11]) gives the parameters of Clough-Penzien model according to the Code for Design of Seismic of Electrical Installations (GB 50260-96 [12]).

\subsection{Coherency Loss Function}

In this paper, the coherency loss function is derived from recorded strong ground motions at SMART-1 array by Hao et al. (Hao et al. [13]; Hao [14]). The coherency loss function between ground motions at two points $i$ and $j$ on ground surface is

$\gamma_{i j}\left(\omega, d_{i j}\right)=\left|\gamma_{i j}\left(\omega, d_{i j}\right)\right| e^{-i o d_{i j} / v_{a p p}}$

where, $v_{a p p}$ is the apparent wave propagation velocity and the exponential function represents the influence of the wave passage effect. $\left|\gamma_{i j}\left(\omega, d_{i j}\right)\right|$ can be expressed as

$\left|\gamma_{i j}\left(\omega, d_{i j}^{l}, d_{i j}^{t}\right)\right|=\exp \left[-\left(\beta_{1}\left|d_{i j}^{l}\right|+\beta_{2} \mid d_{i j}^{t}\right)\right] \cdot \exp \left\{-\left[a_{1}(\omega) \sqrt{\left|d_{i j}^{l}\right|}+a_{2}(\omega) \sqrt{\left|d_{i j}^{t}\right|}\right]\left(\frac{\omega}{2 \pi}\right)^{2}\right\}$

in which $d_{i j}^{l}$ and $d_{i j}^{t}$ are the projected and vertical distance in the wave propagation direction between points $i$ and $j$ on ground surface, respectively. $\alpha_{1}(\omega)$ and $\alpha_{2}(\omega)$ are functions with the form

$$
\begin{aligned}
& a_{1}(\omega)=\left\{\begin{array}{lc}
2 \pi a / \omega+b \omega / 2 \pi+c, & 0.314 \mathrm{rad} / \mathrm{s} \leq \omega \leq 62.83 \mathrm{rad} / \mathrm{s} \\
0.1 a+10 b+c, & \omega \geq 62.83 \mathrm{rad} / \mathrm{s}
\end{array}\right. \\
& a_{2}(\omega)=\left\{\begin{array}{lc}
2 \pi \mathrm{d} / \omega+e \omega / 2 \pi+g, & 0.314 \mathrm{rad} / \mathrm{s} \leq \omega \leq 62.83 \mathrm{rad} / \mathrm{s} \\
0.1 d+10 e+g, & \omega \geq 62.83 \mathrm{rad} / \mathrm{s}
\end{array}\right.
\end{aligned}
$$

where, the constant $a, b, c, d, e, g, \beta_{1}$ and $\beta_{2}$ can be obtained by least-squares fitting the coherency function of recorded motions. The constants in coherency function are $a=3.583 \times 10^{-3}$, $b=-1.811 \times 10^{-5}, \quad c=1.177 \times 10^{-4} d=5.163 \times 10^{-3}, e=-7.583 \times 10^{-6}, g=-1.905 \times 10^{-4}, \beta_{1}=1.109 \times 10^{-4}$, and $\beta_{2}=6.730 \times 10^{-5}$, which were obtained by processing recorded motions during event 45 at the SMART-1 array. In order to compare the change of the coherency loss, different degrees of 
coherency loss are selected according to the previous study (Bi et al. [15]).

\subsection{Simulation of Non-uniform Ground Motions}

A stochastic approach based on random vibration analysis is used, and the simulated ground motion time history is iterated to be compatible with the response spectrum defined in Code for Design of Seismic of Electrical Installations. The transmission tower-line system is assumed to be located in the medium firm soil with peak longitudinal ground acceleration $0.4 \mathrm{~g}$. The intensity of the transverse component and vertical component, as stated in the code, are 0.85 and 0.65 times of the longitudinal component, respectively. According to Penzien and Watable's research (Penzien and Watabe [16]), the three components of ground motions along a set of principal axes are uncorrelated. In this study, the three components of the ground motion are assumed to be directed along the principal axes. Based on the above method, multi-support and multi-component ground motions time histories are generated. Figure 5 gives acceleration time histories of all base points of transmission tower in the three-dimensional direction.
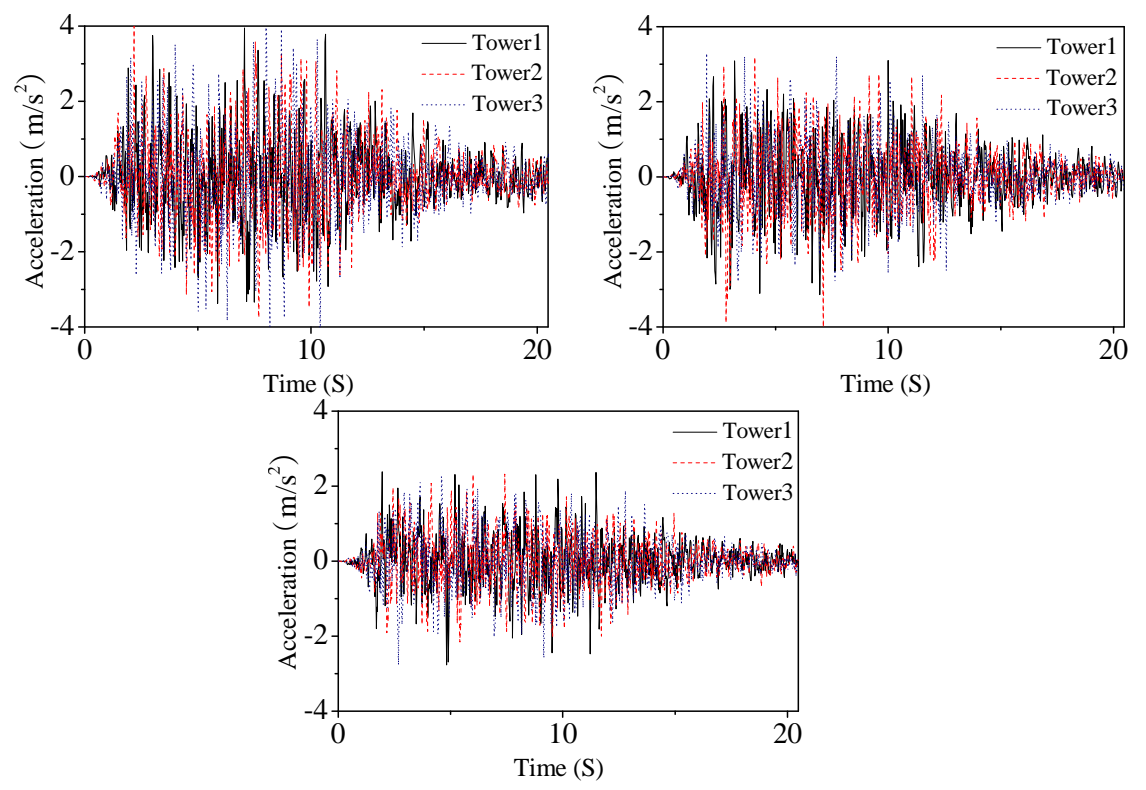

(a) Longitudinal direction

(b) Transverse direction

(c) Vertical direction

Figure 5. Acceleration Time Histories of All Base Points of Transmission Tower in Three-dimensional Direction

\section{NUMERICAL ANALYSIS AND DISCUSSION}

Seismic responses of the straight line type and broken line type transmission tower-line systems subjected to spatially varying ground motions are analyzed using nonlinear time history analysis method. The geometric nonlinearity is taken into account due to large deformation, and the effect of $P-\Delta$ is also considered. The damping ratios of the tower and line are assumed to be 0.02 and 0.01 , respectively. The HHT method is applied in the numerical integration. In order to obtain reliable calculation results, three independent numerical calculations are carried out using the three sets of independently simulated spatial ground motions as input. Mean value are obtained from the three numerical calculation results.

\subsection{Analysis Case}


A total of 17 cases, seismic excitations of spatially varying ground motions are shown in Table 1. Firm, medium firm, medium soft and soft sites are denoted by F, MF, MS, S, respectively. Case 1 is the uniform excitation, because apparent velocity, coherency and soil condition are infinite, completely correlated and medium firm site, respectively. In order to investigate the effect of wave passage influence on the structural response, the coherency and soil condition of case 2 10 are highly correlated and medium firm site, respectively. To research the effect of coherency loss influence on the structural response, the apparent wave and soil condition of case 6, 11 14 are $1000 \mathrm{~m} / \mathrm{s}$ and medium firm site, respectively. To study the effect of local soil condition influence on the structural response, the apparent wave and coherency of case $6,15 \sim 17$ are $1000 \mathrm{~m} / \mathrm{s}$ and highly correlated, respectively.

Table 1. Analysis Cases of Non-uniform Seismic Excitations

\begin{tabular}{|c|c|c|c|c|c|}
\hline \multirow{2}{*}{ Case } & \multirow{2}{*}{$\begin{array}{c}\text { Apparent } \\
\text { velocity }\end{array}$} & \multirow{2}{*}{ Coherency } & \multicolumn{3}{|c|}{ Soil condition } \\
\cline { 4 - 6 } & Case 1 & $1^{\#}$ tower & $2^{\#}$ tower & $3^{\#}$ tower \\
\hline Case 2 & $200 \mathrm{~m} / \mathrm{s}$ & Perfectly & MF & MF & MF \\
\hline Case 3 & $400 \mathrm{~m} / \mathrm{s}$ & Highly & MF & MF & MF \\
\hline Case 4 & $600 \mathrm{~m} / \mathrm{s}$ & Highly & MF & MF & MF \\
\hline Case 5 & $800 \mathrm{~m} / \mathrm{s}$ & Highly & MF & MF & MF \\
\hline Case 6 & $1000 \mathrm{~m} / \mathrm{s}$ & Highly & MF & MF & MF \\
\hline Case 7 & $1200 \mathrm{~m} / \mathrm{s}$ & Highly & MF & MF & MF \\
\hline Case 8 & $1600 \mathrm{~m} / \mathrm{s}$ & Highly & MF & MF & MF \\
\hline Case 9 & $2000 \mathrm{~m} / \mathrm{s}$ & Highly & MF & MF & MF \\
\hline Case 10 & $3000 \mathrm{~m} / \mathrm{s}$ & Highly & MF & MF & MF \\
\hline Case 11 & $1000 \mathrm{~m} / \mathrm{s}$ & Uncorrelated & MF & MF & MF \\
\hline Case 12 & $1000 \mathrm{~m} / \mathrm{s}$ & Weakly & MF & MF & MF \\
\hline Case 13 & $1000 \mathrm{~m} / \mathrm{s}$ & Intermediately & MF & MF & MF \\
\hline Case 14 & $1000 \mathrm{~m} / \mathrm{s}$ & Completely & MF & MF & MF \\
\hline Case 15 & $1000 \mathrm{~m} / \mathrm{s}$ & Highly & F & MF & F \\
\hline Case 16 & $1000 \mathrm{~m} / \mathrm{s}$ & Highly & MS & MF & MS \\
\hline Case 17 & $1000 \mathrm{~m} / \mathrm{s}$ & Highly & S & MF & S \\
\hline
\end{tabular}

\subsection{Effect of Wave Passage}

To study the effect of apparent velocity, nine different velocities of wave propagation are considered in the analysis, $200 \mathrm{~m} / \mathrm{s}$ (Case 2), $400 \mathrm{~m} / \mathrm{s}$ (Case 3), $600 \mathrm{~m} / \mathrm{s}$ (Case 4), $800 \mathrm{~m} / \mathrm{s}$ (Case 5), $1000 \mathrm{~m} / \mathrm{s}$ (Case 6), $1200 \mathrm{~m} / \mathrm{s}$ (Case 7), $1600 \mathrm{~m} / \mathrm{s}$ (Case 8), $2000 \mathrm{~m} / \mathrm{s}$ (Case 9) and $3000 \mathrm{~m} / \mathrm{s}$ (Case 10 ), to cover the range of practical propagation velocities in the engineering. In all these cases, the coherency loss and soil condition of ground motion are assumed to be highly correlated and the medium firm site, respectively. 
Table 2. Comparison of Displacements at the Top of Tower under Different Traveling Wave Velocities

\begin{tabular}{|c|c|c|c|c|}
\hline \multirow{2}{*}{ Case } & \multicolumn{2}{|c|}{ Straight line type } & \multicolumn{2}{c|}{ Broken line type } \\
\cline { 2 - 5 } & Longitudinal & Transverse & Longitudinal & Transverse \\
\hline Case 1 & 1.00 & 1.00 & 1.00 & 1.00 \\
\hline Case 2 & 6.56 & 1.10 & 4.20 & 1.37 \\
\hline Case 3 & 6.18 & 1.06 & 3.26 & 1.31 \\
\hline Case 4 & 3.68 & 1.11 & 2.65 & 1.34 \\
\hline Case 5 & 2.53 & 1.37 & 2.03 & 1.37 \\
\hline Case 6 & 1.68 & 1.03 & 1.61 & 1.48 \\
\hline Case 7 & 1.37 & 1.04 & 1.58 & 1.22 \\
\hline Case 8 & 1.44 & 1.05 & 1.42 & 1.11 \\
\hline Case 9 & 1.36 & 1.05 & 1.33 & 1.13 \\
\hline Case 10 & 1.46 & 1.10 & 1.30 & 1.05 \\
\hline
\end{tabular}

The response of the structure under uniform excitation is normalized. The normalized displacements at the top of $2^{\#}$ tower under different traveling wave velocities are given in Table 2 . It can be seen from the table that the longitudinal displacements of the straight line type and broken line type have a decreasing tendency with the increasing wave velocity, but those all larger than that under uniform excitation, and the amplification of the straight line type is larger than that of the broken line type. For the transverse displacement, the difference between the straight line type and the broken line type is very large, and the amplification of the broken line type is greatly larger than that of the straight line type.

The maximum values of the axial force of $2^{\#}$ transmission tower under different traveling wave velocities are shown in Figure 6. It can be seen from the figure 6 that the variations of the two type models are similar. The axial forces increase gradually with the decrease of the traveling wave velocities. The maximum axial forces of two type models appear when the velocity is $200 \mathrm{~m} / \mathrm{s}$, and the axial forces are 3.7 and 2.2 times as the cases under uniform excitation, respectively. The axial forces considering wave passage effect are larger than those under uniform excitation. The change of the axial force of the straight line type system is very little when the velocity exceeds $1000 \mathrm{~m} / \mathrm{s}$, but the axial forces of the broken line type system decrease gradually with the increasing velocity.

Figure 7 shows the maximum value curves of the vertical displacements of transmission lines under different traveling wave velocities. Owing to the effect of the broken line, the shapes of the vertical displacements have changed. The variations of the two type models considering wave passage effect are similar. With the decrease of traveling wave velocities, the vertical displacements of transmission lines increase and are amplified strongly. The vertical displacements of transmission lines decrease with the increasing wave velocity. When the velocity exceeds $1000 \mathrm{~m} / \mathrm{s}$, the variations of the displacements of two type models are very little but all displacements are larger than those under uniform excitation.

As shown in Figure 8, the maximum value curves of tension forces of transmission lines under different traveling wave velocities are given. It can be seen from the figure 8 that the tension forces of two type models considering wave passage effect are larger than those under uniform excitation. The maximum tension forces of transmission lines of the two type models can be obtained when 
the velocity is $400 \mathrm{~m} / \mathrm{s}$, and the others velocities have different influence on the two type models. With the increasing velocity, the tension forces decrease gradually and are close to the response of structure under uniform excitation. Neglecting the wave passage effect of ground motion, the tension forces of transmission lines of the two type models could be underestimated by more than $160 \%$.

According to the variations of the displacement and internal force responses of transmission tower and transmission lines considering the change of traveling wave velocity, the wave passage effect has a significant influence on the straight line type and broken line type structures. The responses of the two type models are very large when the wave velocities are low, and the responses of the two type models decrease gradually with the increasing wave velocity and are close to the cases under uniform excitation. Different traveling wave velocities have different influence on the responses of the two type models. Therefore, the traveling wave velocity can not be ignored for the straight line type and broken line type systems.

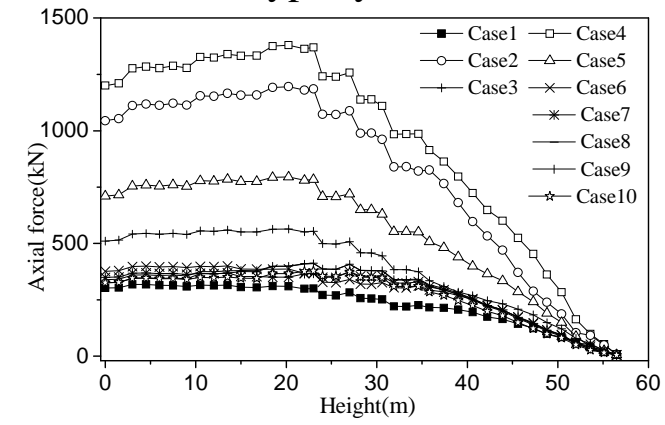

(a) Straight line type

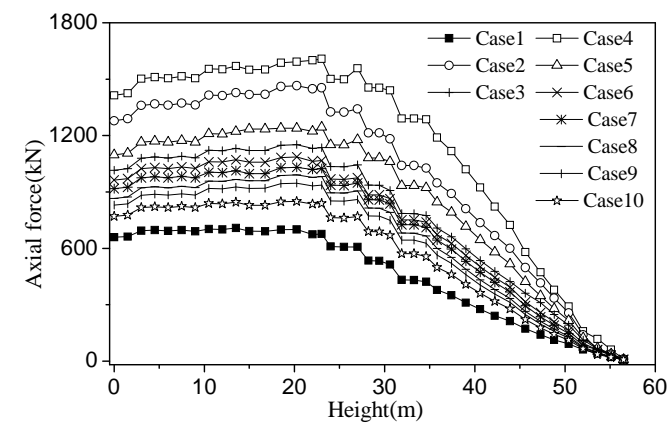

(b) Broken line type

Figure 6. Axial Forces of Tower under Different Traveling Wave Velocities

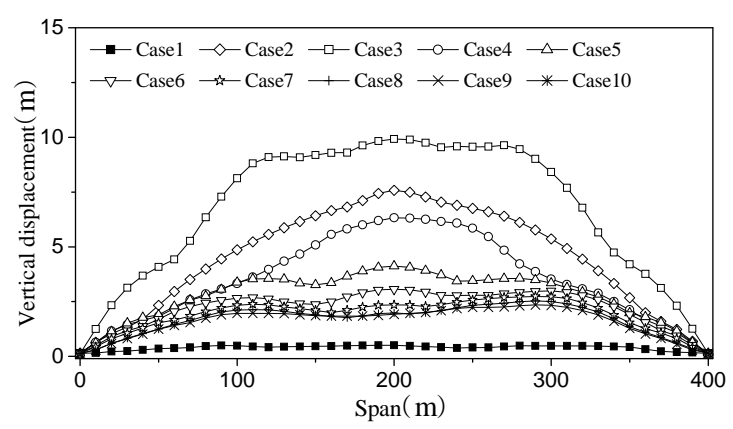

(a) Straight line type

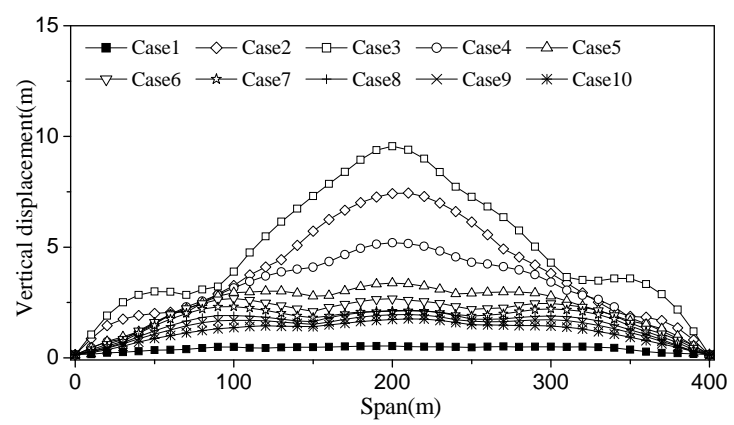

(b) Broken line type

Figure 7. Vertical Displacements of Transmission Lines under Different Traveling Wave Velocities

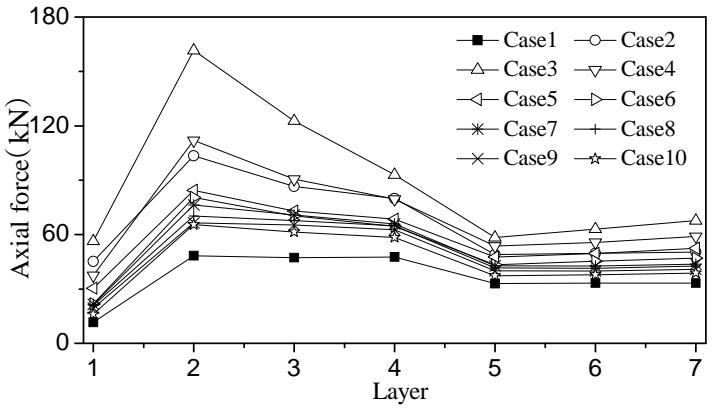

(a) Straight line type

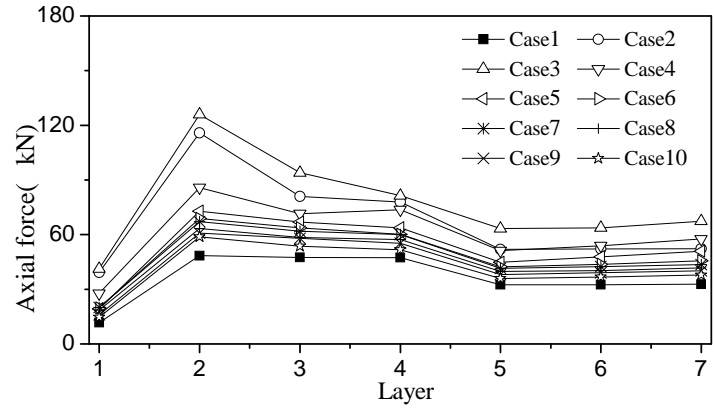

(b) Broken line type

Figure 8. Tension Forces of Transmission Lines under Different Traveling Wave Velocities 


\subsection{Effect of Coherency Loss}

To investigate the effect of coherency loss, uncorrelated (Case 11), weakly (Case 12), intermediately (Case 13), highly (Case 6), and completely correlated (Case 14) ground motions are considered, respectively. It should be noted that the correlation as low as uncorrelated does not usually occur at short distances, unless there are considerable changes in the local geology from one support to the other. In all these cases, the apparent velocity and soil condition of ground motion are assumed to be $1000 \mathrm{~m} / \mathrm{s}$ and the medium firm site, respectively.

The response of the structure under uniform excitation is normalized. Table 3 shows the normalized displacements at the top of $2^{\#}$ tower under different degrees of coherency loss. The longitudinal displacement of the straight line type system increases with the decrease of the degree of coherency loss, but the variation of the broken line type system's displacement is little with the change of the degree of coherency loss. The transverse displacement of the straight line type has an increasing tendency with the decrease of the degree of coherency loss, and its amplification varies significantly. The transverse displacement of the broken line type system has changed indistinctively with the degree of coherency loss varying.

Table 3. Comparison of Displacements at the Top of Tower under Different Degrees of Coherency Loss

\begin{tabular}{|c|c|c|c|c|}
\hline \multirow{2}{*}{ Case } & \multicolumn{2}{|c|}{ Straight line type } & \multicolumn{2}{c|}{ Broken line type } \\
\cline { 2 - 5 } & Longitudinal & Transverse & Longitudinal & Transverse \\
\hline Case 1 & 1.00 & 1.00 & 1.00 & 1.00 \\
\hline Case 11 & 1.61 & 0.97 & 1.38 & 1.28 \\
\hline Case 12 & 1.68 & 1.03 & 1.61 & 1.48 \\
\hline Case 13 & 2.40 & 1.30 & 2.20 & 1.35 \\
\hline Case 6 & 3.16 & 1.51 & 2.38 & 1.39 \\
\hline Case 14 & 5.03 & 1.54 & 3.04 & 1.36 \\
\hline
\end{tabular}

Figure 9 shows the maximum values of axial force of $2^{\#}$ transmission tower under different degrees of coherency loss. It can be seen from the figure that the responses of two type models have an increasing tendency with the decrease of the degree of coherency loss. The maximum axial forces appear when the coherency loss is uncorrelated, and the axial forces of two type models are 3.7 and 2.2 times as the cases under uniform excitation, respectively. The degree of coherency loss has a significant influence on the variation of transmission tower's axial forces, and the axial forces have a decreasing tendency with the degree of coherency loss increasing.

As shown in Figure 10, the maximum value curves of the vertical displacements of transmission lines under different degrees of coherency loss. Two type models have an increasing tendency with the decrease of the degree of coherency loss. The change of coherency loss has a great influence on the vertical displacement of transmission lines for the straight line type system, but the vertical displacements of transmission lines are affected insignificantly by the change of coherency loss except for uncorrelated and weakly correlated.

The maximum value curves of tension forces of transmission lines under different degrees of coherency loss are shown in Figure 11. The change of coherency loss has little influence on the tension force of transmission line for the straight line type system, so the change of coherency loss can be ignored. The tension forces of transmission lines are affected slightly by the change of 
coherency loss except for uncorrelated and weakly correlated for the broken line type system. Neglecting the coherency loss effect of ground motion, the tension forces of transmission lines of two type models could be underestimated by more than $80 \%$ and $120 \%$, respectively.

The variations of the displacement and internal force responses of transmission tower and transmission lines considering the change of coherency loss can be obtained from the above analysis. The change of the degree of coherency loss has a great influence on the responses of the two type models except for the tension forces of transmission lines for the straight line type. The responses of structures are affected insignificantly by the change of coherency loss except for uncorrelated and weakly correlated for the broken line type system, but the correlation as low as uncorrelated and weakly occur at long distances, so the change of coherency loss could not be considered at short distances. Neglecting the coherency loss effect of ground motion could underestimate the responses of the straight line type and broken line type systems.

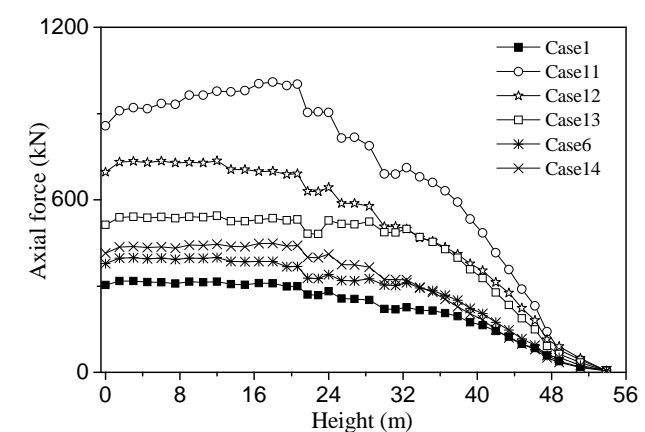

(a) Straight line type

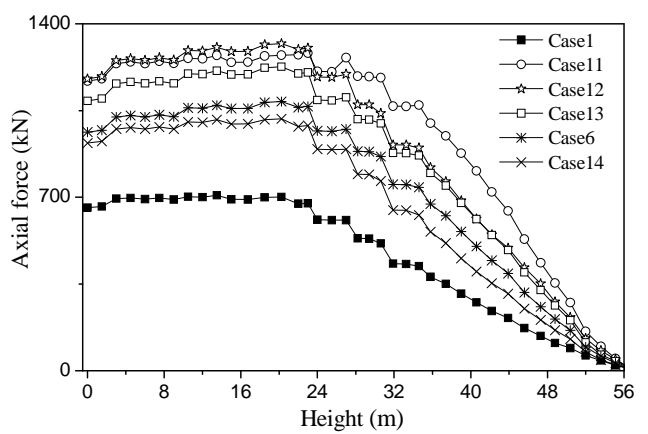

(b) Broken line type

Figure 9. Axial Forces of Tower under Different Degrees of Coherency Loss

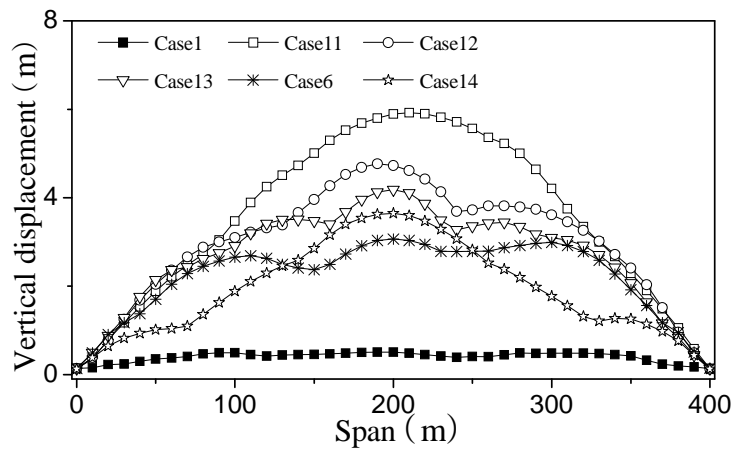

(a) Straight line type

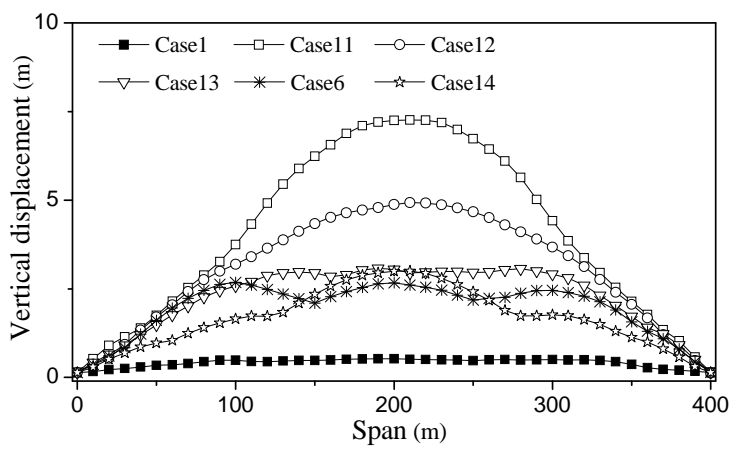

(b) Broken line type

Figure 10. Vertical Displacements of Transmission Lines under Different Degrees of Coherency Loss

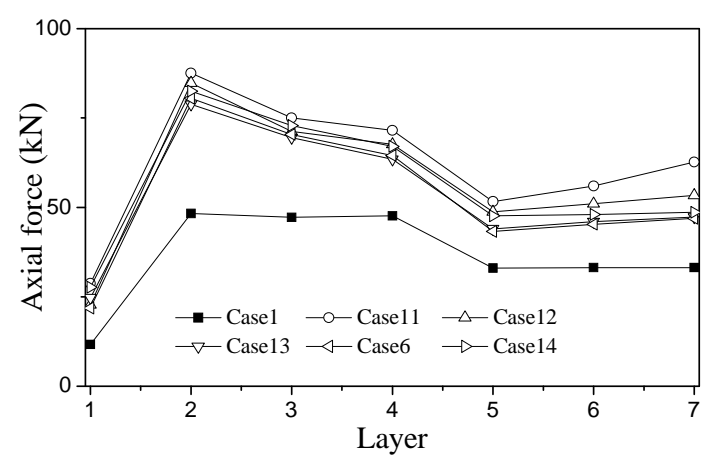

(a) Straight line type

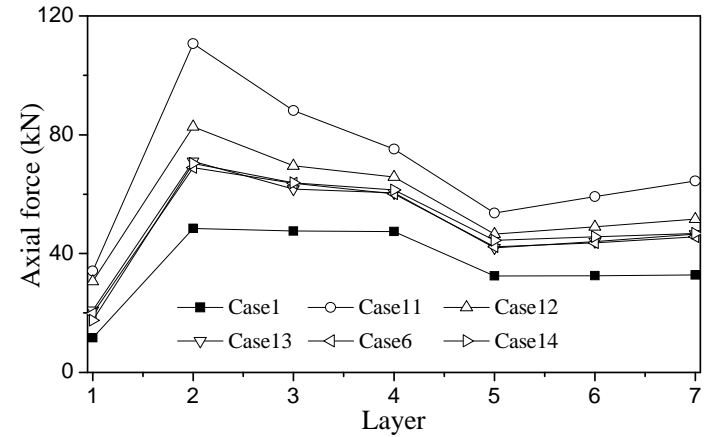

(b) Broken line type

Figure 11. Tension Forces of Transmission Lines under Different Degrees of Coherency Loss 


\subsection{Effect of Local Site}

In order to research the effect of local site, MF-MF-MF (Case 6), F-MF-F (Case 15), MS-MF-MS (Case 16) and S-MF-S (Case 17) are considered. In all these cases, the apparent velocity and coherency of ground motion are assumed to be $1000 \mathrm{~m} / \mathrm{s}$ and highly correlated, respectively.

The response of the structure under uniform excitation is normalized. Table 4 shows the normalized displacements at the top of $2^{\#}$ tower under different site conditions. The longitudinal displacements of the straight line type and broken line type structures increase with the degree of the difference of the site condition increasing. The change of site condition has little influence on the transverse displacement of two type models, but the amplification of the broken line type system is larger than that of the straight line type system.

Table 4. Comparison of Displacements at the Top of Tower under Different Site Conditions

\begin{tabular}{|c|c|c|c|c|}
\hline \multirow{2}{*}{ Case } & \multicolumn{2}{|c|}{ Straight line type } & \multicolumn{2}{c|}{ Broken line type } \\
\cline { 2 - 5 } & Longitudinal & Transverse & Longitudinal & Transverse \\
\hline Case 1 & 1.00 & 1.00 & 1.00 & 1.00 \\
\hline Case 6 & 1.68 & 1.03 & 1.61 & 1.48 \\
\hline Case 15 & 2.20 & 1.03 & 1.77 & 1.39 \\
\hline Case 16 & 1.62 & 1.04 & 1.62 & 1.36 \\
\hline Case 17 & 2.32 & 1.07 & 1.94 & 1.54 \\
\hline
\end{tabular}

Figure 12 shows the maximum values of axial force of $2^{\#}$ transmission tower under different site conditions. The site condition has obvious influence on the response of the straight line type system, and the axial force of the tower in the different sites is larger than that in the same site. The site condition has a significant influence on the response of the broken line type system, and the response increases with the degree of the difference of the site condition increasing.

As shown in Figure 13, the maximum value curves of the vertical displacements of transmission lines under different site conditions are given. The great differences of site conditions magnify strongly the vertical displacement of transmission line for the straight line type system, but the change of vertical displacement is little when the difference of site conditions is small. The vertical displacement increases gradually with the degree of the difference of site condition increasing for the broken line type system.

The maximum value curves of tension forces of transmission lines under different site conditions are shown in Figure 14. The tension forces of the two type models increase gradually with the degree of the difference of site condition increasing, but the amplification of the straight line type system is larger than that of the broken line type system. Neglecting the local site effect of ground motion, the tension forces of transmission lines of two type models could be underestimated by more than $100 \%$ and $70 \%$, respectively.

The variations of the displacement and internal force responses of transmission tower and transmission lines considering different site conditions can be obtained from the above observations. The two type models have an increasing tendency with the degree of the difference of site conditions increasing. The change of the site conditions has a greater influence on the response of the straight line type system than that of the broken line type system. Therefore, it is necessary to consider the local site effect of ground motion, especially for the straight line type system. 


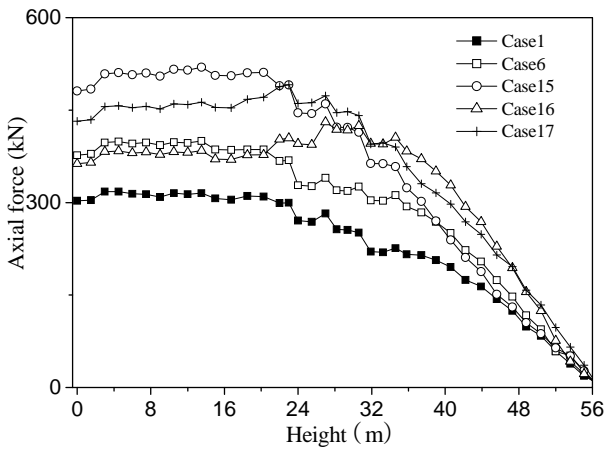

(a) Straight line type

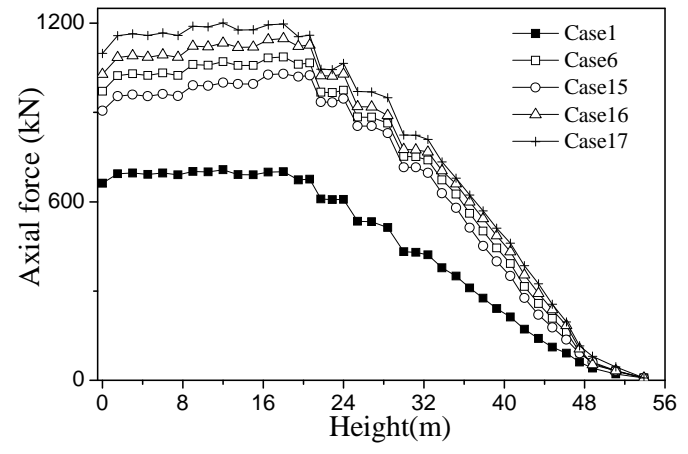

(b) Broken line type

Figure 12. Axial Forces of Tower under Different Site Conditions

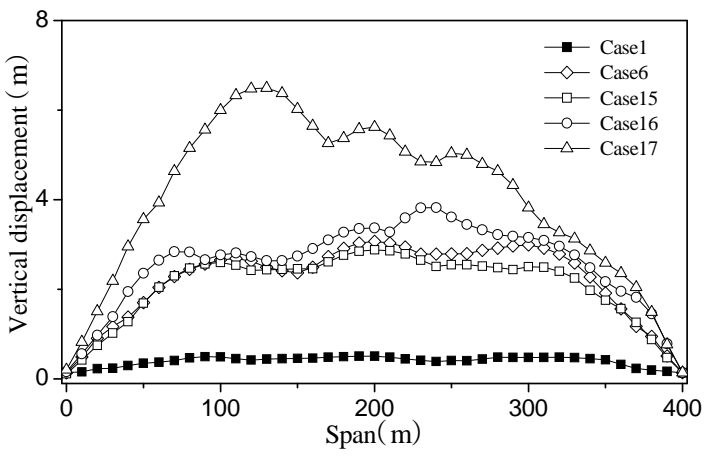

(a) Straight line type

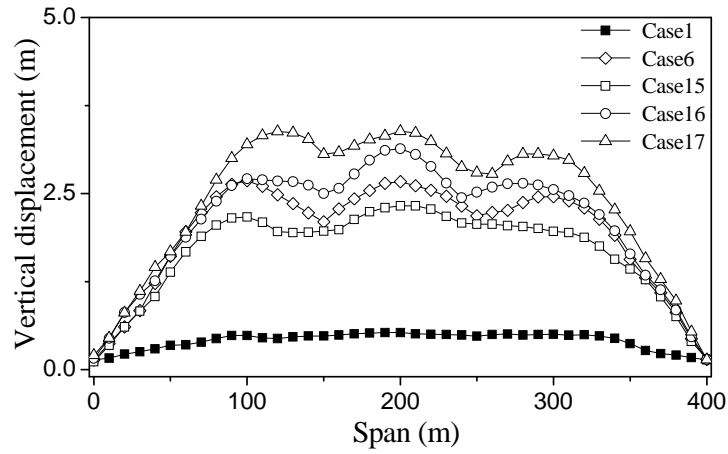

(b) Broken line type

Figure 13. Vertical Displacements of Transmission Lines under Different Site Conditions

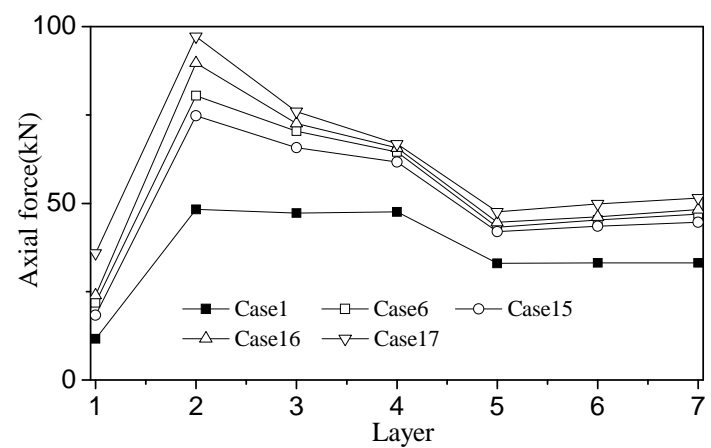

(a) Straight line type

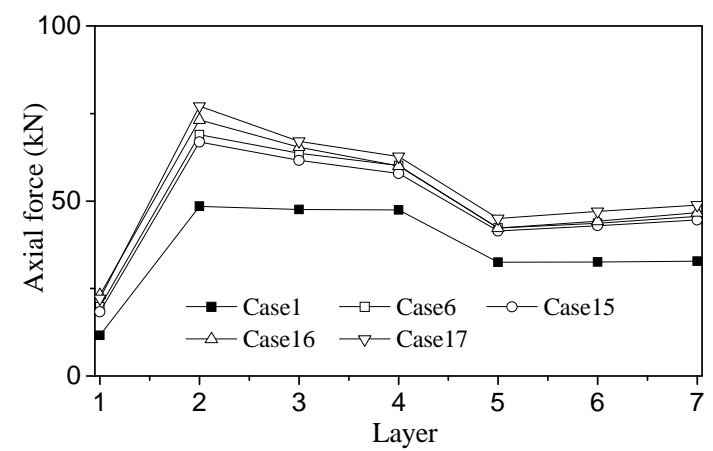

(b) Broken line type

Figure 14. Tension Forces of Transmission Lines under Different Site Conditions

\section{CONCLUSIONS}

The effect of non-uniform ground motions on the response of the straight line type and broken line type transmission tower-line systems have been investigated in this paper. The influence of wave passage effect, coherency loss effect and different local site effect on the system are considered, respectively. Based on the numerical results and analysis, the following conclusions are drawn:

(1) The wave passage effect has a significant influence on both the straight line type and broken line type models. Neglecting the wave passage effect in analysis, the structural responses would be underestimated. The traveling wave velocity can not be ignored for the straight line type and broken line type systems. 
(2) The change of the degree of coherency loss has a great influence on the response of structures except for the tension forces of transmission lines for the straight line type system. The responses of structures are affected insignificantly by the change of coherency loss except for uncorrelated and weakly correlated for the broken line type system. Neglecting the coherency loss effect of ground motion, the responses of the straight line type and broken line type systems would be underestimated.

(3) The two type models have an increasing tendency with the degree of the difference of site conditions increasing. It is necessary to consider the local site effect of ground motion, especially for the straight type system.

This study demonstrates that the non-uniform seismic excitations are very important to not only the straight line type transmission tower-line system but also the broken line type transmission tower-line system. In order to obtain a general conclusion, more studies should be investigated about broken line type transmission tower-line system.

\section{ACKNOWLEDGEMENTS}

This research work was jointly supported by the National Natural Science Foundation of China (Grant No. 51208285), China Postdoctoral Science Foundation funded project (Grant No. 2012M521338), Shandong Province Natural Science Foundation of China (Grant No. ZR2012EEQ005) and Independent Innovation Foundation of Shandong University of China (Grant No. 2011GN051)

\section{REFERENCES}

[1] Yin, R.H., Li, D.L. Liu, G.L. and Zhai, T., "Seismic Damage and Analysis of Power Transmission Towers”, World Earthquake Engineering, 2005, Vol. 21, No. 1, pp. 51-54.

[2] Zerva, A. and Harada, T., "Response of a Rigid Foundation to a Spatially Random Ground Motion”, Earthquake Engineering and Structural Dynamics, 1992, Vol. 21, No. 8, pp. 713-740.

[3] Ghobarah, A., Aziz, T.S., and El-Attar, M., "Response of Transmission Lines to Multiple Support Excitation”, Engineering Structure, 1996, Vol. 18, No. 12, pp. 936-946.

[4] Li, H.N., Shi, W.L. and Jia, L.G., "Simplified Aseicmic Calculation Method Considering Effects of Line on Transmission Tower", Journal of Vibration Engineering, 2003, Vol. 16, No. 2, pp. 233-237.

[5] Li, H.N., Shi, W.L. and Jia, L.G., "Limitations of Effects of Lines on In-plane Vibration of Transmission Towers and Simplified Seismic Calculation Method”, Vibration and Impact, 2004, Vol. 23, No. 2, pp. 1-7.

[6] Li, H.N., Shi, W.L., Wang, G.X. and Jia, L.G., "Simplified Models and Experimental Verification for Coupled Transmission Tower-line System to Seismic Excitations”, Journal of Sound and Vibration, 2005, Vol. 286, No. 3, pp. 565-585.

[7] Tian, L., Li, H.N. and Huang, L. Zh., "Lateral Response of Transmission Tower-line System under Multiple Support Excitations”, Proceeding of the Chinese Society for Electrical Engineering, 2008, Vol. 28, No. 16, pp. 108-114.

[8] Deng, H. Zh., Chen, X.M., Tu, H.M., Ma, X. and Wang, Zh. M., “Experimental Study on Model of Jiangyin Long Span Transmission Tower”, Journal of Building Structures, 2001, Vol. 22, No. 6, pp. 31-35. 
[9] Shen, Sh. Zh., Xu, Ch. B. and Zhao, Ch., "Design of Suspension Structure”, China Architecture and Building Press, 1997.

[10] Clough, R.W. and Penzien, J., “Dynamics of structures”, McGraw-Hill Education, 1975.

[11] Tian, L. and Li, H.N., "Parameter Study on Seismic Random Model Based on Code for Design of Seismic of Electrical Installations", Journal of Disaster Prevention and Mitigation Engineering, 2010, Vol. 30, No. 1, pp. 17-22.

[12] GB 50260-96, “Code for Seismic Design of Electrical Facilities”, China Plan Press, 1996.

[13] Hao, H., Oliveira, C.S. and Penzien, J., "Multiple-station Ground Motion Processing and Simulation based on SMART-1 Array Data”, Nuclear Engineering and Design, 1989, Vol. 111, pp. 1325-1345.

[14] Hao, H., "Effects of Spatial Variation of Ground Motions on Large Multiply-supported Structures”, Report No. UCB/EERC-89/06, 1989.

[15] Bi, K.M., Hao, H. and Chou, W.N., "Required Separation Distance between Decks and at Abutments of a Bridge Crossing a Canyon Site to Avoid Seismic Pounding”, Earthquake Engineering and Structural Dynamics, 2009, Vol. 39, No. 3, pp. 303-323.

[16] Penzien, J. and Watabe, M., "Characteristics of 3-dimensional Earthquake Ground Motions”, Earthquake Engineering and Structural Dynamics, 1975, Vol. 4, pp. 365-373. 